\section{Authentication of European sea bass according to production method and geographical origin by light stable isotope ratio and rare earth elements analyses combined with chemometrics}

\author{
Maria Olga Varrà, ${ }^{1}$ Sergio Ghidini, ${ }^{1}$ \\ Emanuela Zanardi, ${ }^{1}$ Anna Badiani, ${ }^{2}$ \\ Adriana Ianieri ${ }^{1}$
}

${ }^{1}$ Department of Food and Drug, University of Parma; ${ }^{2}$ Department of Veterinary Medical Science, University of Bologna, Italy

\begin{abstract}
In this work, stable isotope ratio (SIR) and rare earth elements (REEs) analyses, combined with multivariate data elaboration, were used to explore the possibility to authenticate European sea bass (Dicentrarchus labrax L.) according to: i) production method (wild or farmed specimens); ii) geographical origin (Western, Central or Eastern Mediterranean Sea). The dataset under investigation included a total of 144 wild and farmed specimens coming from 17 different European areas located in the Mediterranean Sea basin. Samples were subjected to SIR analysis (carbon and nitrogen) and REEs analysis (lanthanum, europium, holmium, erbium, lutetium, and terbium). Then, Analytical data were handled by Principal Component Analysis (PCA) and then by Orthogonal Partial Last Square Discriminant Analysis (OPLS-DA), to obtain functional classification models to qualitatively discriminate sea bass according to the conditions under study. OPLSDA models provided good correct classification rate both for production method and geographical origin. It was confirmed that chemometric elaboration of data obtained from SIR and REEs analyses can be a suitable tool for an accurate authentication of European sea bass.
\end{abstract}

\section{Introduction}

Authentication of fishery and aquaculture products is of growing interest, due to the expansion and globalization of the fish chain and, on the other hand, by the public awareness concerning food quality and safety.

According to European Legislation, label descriptions of fish must include commercial designation, proper scientific name of the species, production method, and fishing area of provenance (Regulation EU No 1379/2013). Frequently these declared information are unreliable, so they need to be properly validated to ensure compliance with food legislation and traceability requirements, and to protect consumers from commercial food frauds (FAO, 2018).

Several techniques and analytical methods are traditionally used to measure features and properties that can discriminate different origins and production process of food. Among these, stable isotope ratio (SIR) and rare earth elements (REEs) analyses represent high- sensitive and wellestablished methodology, even if they are not yet widely used for authentication of fish.

The natural variation in isotopic abundances of light elements, as hydrogen $(\mathrm{H})$, carbon $(\mathrm{C})$, nitrogen $(\mathrm{N})$, oxygen $(\mathrm{O})$, and sulphur (S) can be largely influenced by the overall environmental conditions of the location from where the products originate. Isotopic composition of fish tissues, in particular, is the result of several complicated factors, such as positions in food chains, kind of feed ingested throughout all life, kinetic fractionation due to metabolism, geographical origin, physiological and anatomic properties, etc. (Ghidini et al., 2006). Thus, results of SIR analysis, if properly interpreted, can provide a unique fingerprint of the fish investigated.

Concentration of REEs has also been proposed to identify geographical origin of different kind of food matrices, because it mainly reflects the conditions of the production environment. REEs content in fishery and aquaculture products is strongly related to the vegetation eaten by fish, which reflects bio-available and mobilized nutrients present in the underlying soils (Drivelos and Georgiou, 2012), but its analytical determination for authentication of food of animal origin is still limited. The increasing use of REEs for high-tech applications, (production of screen displays, glass, lenses, etc.), medical applications (medical x-ray and magnetic resonance image scanning systems), and, in some country like China, for usage as fertilizer or food supplements in animal production, are responsible for losses of REEs in the aquatic system (Mittermüller et al., 2016; Rim, 2016) and for permanent alterations of REEs natural pattern of the aquatic systems (Censi et al., 2004; Li et al., 010; Noack et al., 2014). This anthropogenic inputs of REEs in seawater, if properly studied, may be used to find out from which specific location the fish originate. Thus, the aim of the present work was to verify whether chemometric elaboration of data obtained
Correspondence: Maria Olga Varrà, Department of Food and Drug, University of Parma, Via del Taglio 10, 43126 Parma, Italy. Tel: +39.0521.902761 - Fax: +39.0521.902752. E-mail: mariaolga.varra@studenti.unipr.it

Key words: Fish authentication, Production method, Geographical origin, Stable isotope ratio and rare earths elements Analyses, Chemometrics.

Contributions: the authors contributed equally.

Conflict of interest: the authors declare no potential conflict of interest

Funding: none.

Received for publication: 10 October 2018.

Revision received: 19 February 2019.

Accepted for publication: 19 February 2019.

This work is licensed under a Creative Commons Attribution-NonCommercial 4.0 International License (CC BY-NC 4.0).

(C) Copyright M.O. Varrà et al., 2019

Licensee PAGEPress, Italy

Italian Journal of Food Safety 2019; 8:7872

doi:10.4081/ijfs.2019.7872

both from SIR analysis $\left({ }^{13} \mathrm{C} /{ }^{12} \mathrm{C}\right.$ and ${ }^{15} \mathrm{~N} /{ }^{14} \mathrm{~N}$ isotope ratios) and REEs analysis (lanthanum, La; europium, Eu; holmium, Ho; erbium, Er; lutetium, $\mathrm{Lu}$; terbium, $\mathrm{Tb}$ ) could provide a suitable tool to build classification models to be used for authentication of European sea bass samples according to production method (wild or farmed) and geographical origin (Western, Eastern, or Central Mediterranean Sea).

\section{Materials and Methods}

\section{Sea bass samples}

The sampling of 144 European sea bass (Dicentrarchus labrax L.) was carried out during 2 periods in 2012 (spring-summer, $\mathrm{n}=77$; autumn-winter, $\mathrm{n}=77$ ). All the specimens came from fishing areas (wild subjects, $W ; n=34$ ) or fish farms (farmed subjects, $F ; n=110$ ) located in the Mediterranean basin. Total length (measured from the most anterior part of the fish to the most posterior part of the caudal fin) was $42.7 \pm 8.0 \mathrm{~cm}$ and $35.3 \pm 4.6 \mathrm{~cm}$ for wild and farmed subjects, respectively; the recorded body weight was $930.0 \pm 488.6 \mathrm{~g}$ in wild and $517.9 \pm 183.3 \mathrm{~g}$ in farmed specimens. Farmed samples, moreover, included intensively (submersible or floating cages located in various open sea areas), semiintensively (earthen tanks), and extensively 
(coastal lagoons), reared samples, whose breeding system varied based on the stocking density declared by farmers. From a geographical point of view, the whole dataset was composed by fifty sea bass samples originating from Western Mediterranean Sea (WM; FAO fishing subareas 37.1.2 and 37.1.3), sixty-four from Central Mediterranean Sea (CM; FAO fishing subareas 37.2.1 and 37.2.2) and thirty were from Eastern Mediterranean Sea (EM; FAO fishing subareas 37.3.1).

\section{Stable isotope analysis}

The stable isotopic composition of carbon $\left({ }^{13} \mathrm{C} /{ }^{12} \mathrm{C}\right.$, expressed as $\left.\delta 13 \mathrm{C}\right)$ and nitrogen $\left({ }^{15} \mathrm{~N} /{ }^{14} \mathrm{~N}\right.$, expressed as $\left.\delta 15 \mathrm{~N}\right)$ in sea bass muscle was carried out through the procedure described below: $0.07 \pm 0.01$ and $0.7 \pm 0.1 \mathrm{mg}$ for $\delta 13 \mathrm{C}$ and $\delta 15 \mathrm{~N}$ analyses, respectively, of freeze-dried fillets $(<0.6$ $\mathrm{mm}$ grain size) were analysed by means of an EA/NA-1100 elemental analyser with $\mathrm{CHN}$ configuration in helium continuous flow mode and coupled to a Finnigan Delta Plus XP mass spectrometer (Thermo Finnigan, Bremen, Germany). Sample isotope ratios were then calculated according to international reference standard V-PDB (Vienna PeeDee Belemnite) for $\mathrm{C}$ and atmospheric nitrogen for N. Results were expressed as follows:

$$
\begin{gathered}
\delta(X)=(\mathrm{R} \text { sample }-\mathrm{R} \text { standard }-1) \times \\
1000 \%
\end{gathered}
$$

where $\delta$ is the notation in parts per thousands (\%o) relative to the specific international standard material, $\mathrm{X}$ is the content of ${ }^{13} \mathrm{C}$ or ${ }^{15} \mathrm{~N}$ in the sample, and $\mathrm{R}$ is the molar ratio of the heavy to light isotope of the element $\left(\mathrm{R}={ }^{13} \mathrm{C} /{ }^{12} \mathrm{C}\right.$ or $\left.{ }^{15} \mathrm{~N} /{ }^{14} \mathrm{~N}\right)$.

\section{Rare earth elements analysis}

Sea bass were subjected to mineralization by adding $6 \mathrm{~mL}$ of nitric acid $(67 \%$ purity, Ultrapure Merck, Darmstadt,
Germany) and $2 \mathrm{~mL}$ of hydrogen peroxide (31\% purity, Ultrapure Merck) to $1 \mathrm{~g}$ of sample, through a Milestone 1200 Mega microwave system (FKW S.r.L., Italy). Detection of the elements was obtained by means of Thermo X series inductively coupled plasma mass spectrometry (ICP-MS, Thermo Fisher Scientific, Waltham, MA, U.S.A.).

\section{Statistical analysis}

Independent t-test and analysis of variance (one-way ANOVA) with Tukey HSD post hoc tests were carried out using SPSS software (v. 23.0, SPSS Inc., Chicago, IL, USA), to determine significant differences among the means of each group. The level of significance was $\mathrm{P} \leq 0.05$.

Multivariate data analysis of spectrometric data of SIR and REEs was performed by using SIMCA-P software (v.14.1). Data were firstly normalized by unit of variance (UV) scaling and log-transformed to reduce skewness. Subsequently, principal component analysis (PCA) was performed with the aim to take an overview of data natural structure and, eventually, eliminate strong outliers according to Hotelling's T2 test (at 95\% confidence interval). After that, classification models able to distinguish samples according to their production method and geographical origin were developed by means of a supervised orthogonal partial least square-discriminant analysis (OPLS-DA).

OPLS-DA calibration models were built using only $75 \%$ of the samples (calibration set, $\mathrm{n}=108$ ), while the remaining $25 \%$ of the data was reserved to externally validate OPLS-DA calibration results (prediction set, $n=36$ ). During the external validation stage, the resulting percentage of correctly classified observations and the RMSEP (Root Mean Square Error of Prediction) were evaluated to assess overall classification performances. PCA and OPLS-DA models computed were internal- ly validated by a 7-fold cross-validation (CV) and their quality assessed by the statistical parameters $\mathrm{R}^{2} \mathrm{X}_{\text {cum }}$ (representing goodness of fit), $\mathrm{Q}_{\text {cum }}^{2}$ (representing the goodness of prediction) and, only for OPLS-DA models, $\mathrm{R}^{2} \mathrm{Y}_{\text {cum }}$ (representing total sum of variation explained in $\mathrm{Y}$ matrix). RMSECV (Root Mean Square Error from cross-validation), and RMSEE (Root Mean Square Error of Estimation) were further calculated to evaluate the reliability of the classifiers. Finally, the Variable Influence on Projection (VIP) index for OPLS-DA components was used to identify the most discriminating variables in the OPLS classification. Variables with a VIP value $\geq 1$ were considered significant (Galindo-Prieto et al., 2014).

\section{Results}

\section{REEs concentration and SIR in sea bass samples}

An overview of the results of sea bass isotopic analysis of $\mathrm{C}$ and $\mathrm{N}$ and REEs analysis from different production methods and geographic origins is reported in Table 1. As it can be observed, $\delta^{13} \mathrm{C}$ and $\delta^{15} \mathrm{~N}$ mean values of wild and farmed samples ranged from $-20.33 \%$ to $-17.25 \%$, and from $10.90 \%$ to $14.75 \%$, respectively. Both $\delta^{13} \mathrm{C}$ and $\delta^{15} \mathrm{~N}$ values were significantly higher in wild sea bass compared with farmed ones $(\mathrm{P} \leq 0.05)$. As for geographic provenance, $\mathrm{CM}$ sea bass were found to be isotopically heavier in $\delta^{13} \mathrm{C}$ values $(-18.87 \%$ ) than $\mathrm{EM}$ group $(-21,19 \%$; $\mathrm{P} \leq 0.05)$, while WM samples isotopically heavier in $\delta^{15} \mathrm{~N}$ value (12.80\%) compared to EM and CM group $(\mathrm{P} \leq 0.05)$.

The highest concentrations of almost all REEs were recorded in farmed sea bass on average (Table 1); only Lu values seemed to be higher in wild specimens $(\mathrm{Lu}=0.0538 \mathrm{ng}$

Table 1. Stable isotopic composition of carbon (\%o) and nitrogen (\%o) and rare earth concentrations (ng $\left.\mathrm{g}^{-1}\right)$ of sea bass samples accord-

\begin{tabular}{|c|c|c|c|c|c|}
\hline & \multicolumn{2}{|c|}{ Production } & \multicolumn{3}{|c|}{ Origin } \\
\hline & $W(n=34)$ & $F(n=110)$ & CM $(n=64)$ & WM $(n=50)$ & EM $(n=30)$ \\
\hline$\delta^{13} \mathrm{CPDB}-1$ & $-17.25 \pm 7.12^{\mathrm{a}}$ & $-20.33 \pm 1.08^{b}$ & $-18.87 \pm 5.40^{\mathrm{a}}$ & $-19.60 \pm 1.64^{\text {ab }}$ & $-21.19 \pm 0.73^{b}$ \\
\hline$\delta^{15} \mathrm{NAIR}$ & $14.75 \pm 3.42^{\mathrm{a}}$ & $10.90 \pm 1.32^{b}$ & $11.68 \pm 2.11^{\mathrm{a}}$ & $12.80 \pm 3.39^{\mathrm{b}}$ & $10.45 \pm 0.86^{c}$ \\
\hline $\mathrm{La}$ & $4.6095 \pm 3.4829^{a}$ & $4.9649 \pm 3.2167^{\mathrm{a}}$ & $5.1649 \pm 3.1800^{\mathrm{a}}$ & $5.0074 \pm 3.3683^{\mathrm{a}}$ & $4.0647 \pm 3.3457^{a}$ \\
\hline $\mathrm{Eu}$ & $0.1555 \pm 0.5055^{\mathrm{a}}$ & $0.2651 \pm 0.6319^{a}$ & $0.1858 \pm 0.4954^{\mathrm{a}}$ & $0.3430 \pm 0.7538^{a}$ & $0.1802 \pm 0.5382^{a}$ \\
\hline Ho & $0.0776 \pm 0.0546^{\mathrm{a}}$ & $0.0848 \pm 0.0523^{\mathrm{a}}$ & $0.0857 \pm 0.0488^{a}$ & $0.0876 \pm 0.0600^{\mathrm{a}}$ & $0.0700 \pm 0.0483^{\mathrm{a}}$ \\
\hline Er & $0.3288 \pm 0.2609^{\mathrm{a}}$ & $0.3655 \pm 0.2180^{a}$ & $0.3759 \pm 0.2048^{a}$ & $0.3703 \pm 0.2607^{\mathrm{a}}$ & $0.2939 \pm 0.2203^{\mathrm{a}}$ \\
\hline $\mathrm{Lu}$ & $0.0417 \pm 0.0306^{\mathrm{a}}$ & $0.0538 \pm 0.0345^{\mathrm{a}}$ & $0.0547 \pm 0.0328^{a}$ & $0.0505 \pm 0.0385^{\mathrm{a}}$ & $0.0438 \pm 0.0279^{a}$ \\
\hline $\mathrm{Tb}$ & $1.7955 \pm 1.4363^{\mathrm{a}}$ & $2.0267 \pm 1.5482^{\mathrm{a}}$ & $2.0409 \pm 1.5128^{a}$ & $2.0863 \pm 1.5607^{\mathrm{a}}$ & $1.6352 \pm 1.4958$ \\
\hline
\end{tabular}
ing to production methods (W or F) and geographical origin (CM, WM, or EM) (mean \pm standard deviation).

Mean $\pm \mathrm{SD}(\mathrm{n}=9)$ followed by different letters in the same row (W and F, or CM, WM, and $\mathrm{EM})$ are significantly different $(\mathrm{P} \leq 0.05)$. 
$\left.\mathrm{g}^{-1}\right)$ than in farmed ones $\left(\mathrm{Lu}=0.0417 \mathrm{ng} \mathrm{g}^{-1}\right)$, as well as Eu, Ho and Tb seemed to be higher for WM samples, and $\mathrm{Er}$ and $\mathrm{Lu}$ for $\mathrm{CM}$ samples. Nevertheless, no significantly differences in REEs concentration were found among all the groups $(\mathrm{P} \geq 0.05)$.

\section{Chemometrics}

PCA of the pretreated SIR and REEs data of the 144 sea bass samples was fitted with a total of 5 principal components (PCs) $\left(\mathrm{R}^{2} \mathrm{X}=0.819, \mathrm{Q}^{2}=0.768\right)$ and the first two PCs explained $78 \%$ of the total variation in the original dataset. Despite the good statistics associated to the model, the visual separation among different groups of samples in the bidimensional score plot was not accettable, for both wild/farmed and $\mathrm{CM} / \mathrm{EM} / \mathrm{WM}$ sea bass (data not shown). As a matter of fact, overlapping was observed between them, indicating the non-effectiveness of the unsupervised technique to successfully discriminate samples according to the authentication purposes investigated. Anyway, PCA model don't show outliers (no samples outside the 95\% confidence level according to Hotelling T2 test) and, for this reason, none of them was removed from the dataset for the subsequant elaboration.

Two supervised OPLS-DA models were further built on calibration set $(\mathrm{n}=108)$ and validated by means of a 7-fold cross-validation to avoid overoptimistic and misleading results.

The first model aimed to classify samples by production method (Wvs. F). This model was fitted with 1 predictive components (correlated variation) and 2 orthogonal components (uncorrelated variation), that captured $69 \%$ of the total variation in the $\mathrm{X}$-matrix $\left(\mathrm{R}^{2} \mathrm{X}_{\text {cum }}=0.695\right)$. The predictability power, given by the $\mathrm{Q}_{\text {cum }}^{2}$ parameter, was 0.903 , indicating a good separation capability and the predictive variation contained in the data described $95 \%$ of the class membership information $\left(\mathrm{R}^{2} \mathrm{Y}_{\text {cum }}=0.952\right)$.

The score scatter plot reporting spatial distribution of wild and farmed samples (Figure 1) revealed a high interclass variability along the first predictive component (horizontal direction): the $\mathrm{W}$ sea bass distibuted on the negative side, and the F sea bass along the positive one. At the same time, a remarkable intraclass variability was observed, both for $\mathrm{W}$ and $\mathrm{F}$ samples, which largely distributed also along first orthogonal component (vertical direction).

The second OPLS-DA model aimed to classify samples by geographical provenance (WM vs. CM vs. EM) and it was fitted with 2 predictive components and 3 orthogonal ones.
Even if this three-class model was characterised by lower values of $\mathrm{R}^{2} \mathrm{X}_{\text {cum }}$ (= $0.599), \mathrm{R}^{2} \mathrm{Y}_{\text {cum }}(=0.907)$, and $\mathrm{Q}_{\text {cum }}^{2}(=$ 0.893 ) values compared to model discriminating production methods, it was considered acceptable.

Score scatter plot showing space distribution and grouping of samples according to their geographical class membership, is reported in Figure 2. Three different clusterings were observed: WM samples were distributed along the negative axes of the first predictive component (horizontal direction) and of the second predictive component (vertical direction); EM samples were prevalently distributed along the positive axis of the first predictive component and the neagtive axis of the second predictive component; CM samples were distributed along the positive axis of the second predictive component.

Mean RMSECV and RMSEE values calculated for model discriminating samples by production method were found to be 0.178 and 0.060 , respectively, while for model discriminating samples by prove-

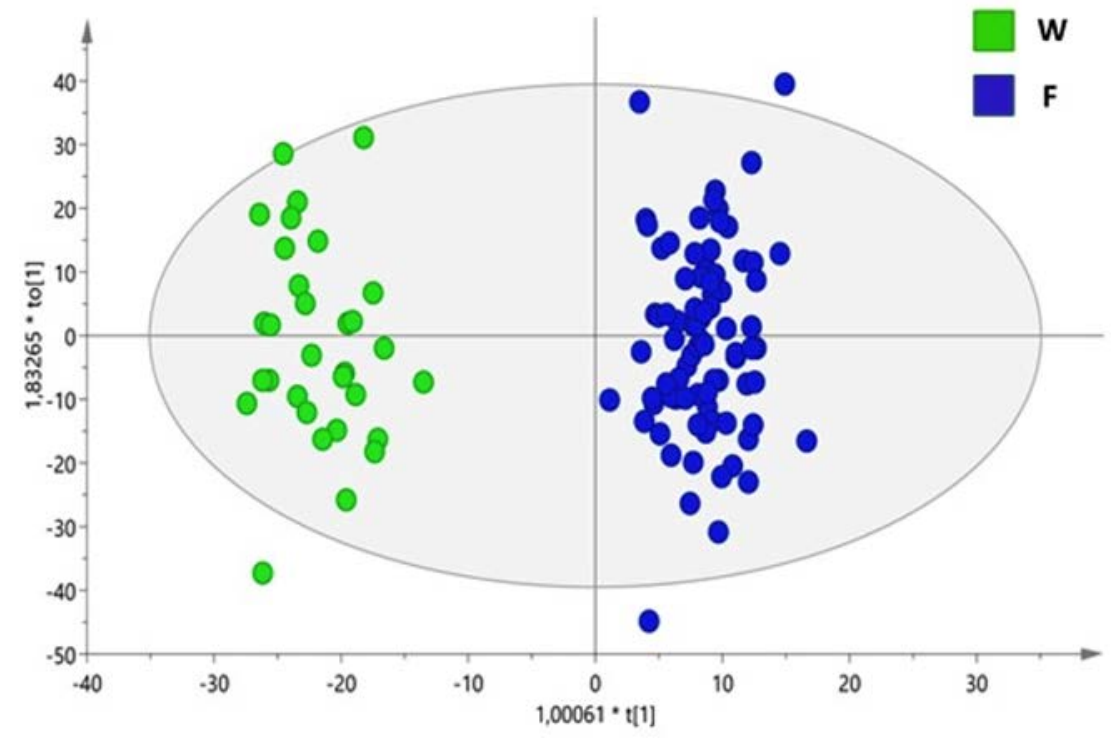

Figure 1. OPLS-DA Score Plot discriminating wild from farmed sea bass ( $W=w i l d ;$ $F=$ farmed).

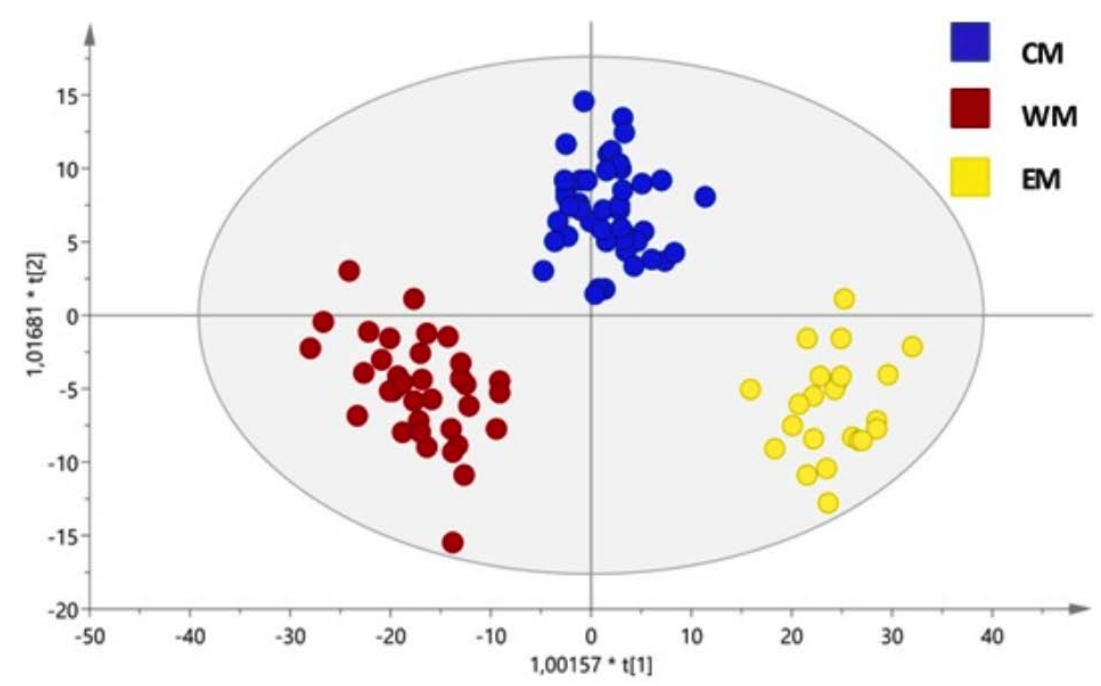

Figure 2. OPLS-DA Score Plot discriminating CM from WM from EM sea bass (CM=central Mediterranean; WM=western Mediterranean; $\mathrm{EM}=$ eastern Mediterranean). 
nance, they were found to be 0.295 and 0.102 , respectively.

Each OPLS-DA model was further tested for predictability of new sea bass samples by using the independent prediction set $(n=36)$. Misclassification table summarizing the proportion of correctly classified observations into the known classes of the prediction set is presented in Table 2. As for production method, it can be observed that $100 \%$ of samples were correctly classified (mean $\mathrm{RMSEP}=0.211$ ), while with regards to geographical origin, some misclassifications occurred, which led to a total correct classification percentage of $90 \%$ of sea bass (mean RMSEP=0.297).

Finally, the VIP index was employed as an indicator of the variables that mostly contributed to discriminate samples in each OPLS-DA models. It was found that $\delta^{15} \mathrm{~N}$ $(\mathrm{VIP}=2.30)$ and $\delta^{13} \mathrm{C}(\mathrm{VIP}=1.45)$ strongly influenced discrimination of $\mathrm{W}$ from $\mathrm{F}$ samples. Similarly, the most relevant variables influencing discrimination by provenance were found to be $\delta^{15} \mathrm{~N}(\mathrm{VIP}=1.23)$ and $\delta^{13} \mathrm{C}$ (1.38), but also $\mathrm{La}(\mathrm{VIP}=1.08)$ and $\mathrm{Ho}$ $(\mathrm{VIP}=1.02)$.

\section{Discussion}

Increasing attention is given to the development of methods for ensuring fish authenticity and discouraging the spreading of fraudulent practises. Light isotopes abundances combined with rare earth elements fingerprinting may represent a valid strategy for this purpose, especially when properly elaborated by chemometrics to develop qualitative discrimination model.

In fishery and aquaculture products, the isotopic abundances $\delta^{13} \mathrm{C}$ and $\delta^{15} \mathrm{~N}$ are linked to the feed habit and to the trophic position of the fish diet, respectively. Wild marine fish tissues are usually isotopically heavier in $\delta^{13} \mathrm{C}$ values than farmed fish, because the dissolved carbon pool of the natural diets of wild fish $\left(\delta^{13} \mathrm{C}=0 \%\right)$ is significantly more enriched than the atmospheric carbon $\left(\mathrm{CO}_{2}\right)$ used for photosynthesis by the terrestrial plants, that can contribute to the formulation of commercial feeds $\left(\delta^{13} \mathrm{C}=-8 \%\right.$ ) (Busetto et al., 2008). As for nitrogen isotopes, fish at higher trophic level also shows higher values of $\delta^{15} \mathrm{~N}$ (Camin et al., 2017), even if these values can be influenced by other factors, such as maturity or growth rate, seasonal isotopic variations in coastal marine environments, and possible spoilage of the fish sample between collection and analysis. Thus, particular attention should be taken to $\delta^{15} \mathrm{~N}$ data interpretation (Morrison et al., 2007).

In the present work, both $\delta^{15} \mathrm{~N}$ and $\delta^{13} \mathrm{C}$ were found to be higher in wild specimens compared to the farmed specimens, to the point of allowing a perfect discrimination of the two populations based just on such knowledge. These results are in accordance to what has been previously reported in literature: studies based on determination of isotopes abundances of $\mathrm{C}$ and $\mathrm{N}$ successfully led to the discrimination between wild and farmed gilthead sea bream (Morrison et al., 2007; Serrano et al., 2007), shrimps (Gamboa-Delgado et al., 2014; Ortea and Gallardo, 2015), Atlantic salmon (Dempson and Power, 2004), and sea bass (Bell et al., 2007). The same method allowed to differentiate three commercial fish (mackerel, yellow croaker and pollock), originating from various countries (Li et al, 2018) and anchovy sampled from inshore habitats, from those from offshore habitats (Tanaka et al., 2010). In our study, values of $\delta^{15} \mathrm{~N}$ and $\delta^{13} \mathrm{C}$ also made the highest contributions in discriminating sea bass by geographical origins, probably because of the differences in prey availability of the various fishing areas or the differences in feed composition used by fish farmers (Moreno Rojas et al., 2007.

The use of REEs as chemical markers for fish provide several advantages (i.e. safety of handling, bioaccumulation, long retention time in tissues, etc.), but few studies have been performed, mainly because of the high accuracy and sensitivity of instruments required for their detection and quantification (Danezis et al., 2016). Early few studies identified samarium as a marker goldfish (Michibata, 1981) as well as dysprosium, europium, and samarium for rainbow trout (Giles and Attas, 1993). Only recently, Pérez de Nanclares et al. (2016) supplemented the fish diet with praseodymium, neodymium, dysprosium, cerium, and lanthanum and successfully discriminated production method and site of origin of salmon samples.

In this work, REEs concentrations did not influence separation of sea bass samples by production method. Despite farmed specimens were characterised by higher contents of mostly the elements studied, these contents were not strictly related to the different feeding input of the two populations. However, Ho e La were found to be influential in the discrimination by geographical provenance, as a result of their natural variability in the marine environment or as a consequence of the anthropogenic pollution.

\section{Conclusions}

In summary, this experiment demonstrates that SIR and REEs analyses combined with multivariate statistics can successfully be used for authentication of European sea bass according to production method and geographical origin. The classification models built were able to correctly discriminate wild from farmed specimens with $100 \%$ of accuracy and samples coming from Western, Central, and Eastern Mediterranean Sea with $89 \%$ of accuracy. Discriminant information, either way, was found to lie prevalently in isotopic abundances of carbon and nitrogen. Additionally, among six rare earth elements measured, lanthanum and holmium showed an important contribution in sample discrimination based on provenance.

Thus, the outcomes of this study demonstrate that differences in composition of the feeding sources and trophic position of fish, that influence the ratio of stable isotope of carbon and nitrogen, as well as the natural or artificial occurrence of REEs in the environment, to which the fish is exposed throughout his life, together could be adopted as an analytical strategy to effectively detect mislabelling involving the origin and thus, guarantee fish and fishery products authenticity.

Table 2. Classification performances tested on prediction set $(n=36)$.

\begin{tabular}{llcc} 
OPLS-DA model & Class & Classification rate per class, \% & Overall classification rate, \% \\
Production method & W & $100.0(8 / 8)$ & $100.0(36 / 36)$ \\
& F & $100.0(28 / 28)$ & $88.9(32 / 36)$ \\
Geographical origin & WM & $92.3(12 / 13)$ & \\
& CM & $81.2(14 / 16)$ & $85.7(6 / 7)$ \\
\hline
\end{tabular}




\section{References}

Bell JG, Preston T, Henderson RJ, Strachan F, Bron JE, Cooper K, Morrison DJ, 2007. Discrimination of wild and cultured European sea bass (Dicentrarchus labrax) using chemical and isotopic analyses. J Agric Food Chem 55:593441.

Busetto ML, Moretti VM, Moreno-Rojas JM, Caprino F, Giani I, Malandra R, Bellagamba F, Guillou CJ, 2008. Authentication of farmed and wild turbot (Psetta maxima) by fatty acid and isotopic analyses combined with chemometrics. J Agric Food Chem 56:2742-50.

Camin F, Boner M, Bontempo L, FauhlHassek C, Kelly SD, Riedl J, Rossmann, A, 2017. Stable isotope techniques for verifying the declared geographical origin of food in legal cases. Trends Food Sci Technol 61:17687.

Censi P, Mazzola S, Sprovieri M, Bonanno A, Patti B, Punturo R, Alonzo G, 2004. Rare earth elements distribution in seawater and suspended particulate of the Central Mediterranean Sea. Chem Ecol 20:323-43.

Danezis GP, Tsagkaris AS, Brusic V, Georgiou CA, 2016. Food authentication: state of the art and prospects. Curr Opin Food Sci 10:22-31.

Dempson JB, Power M, 2004. Use of stable isotopes to distinguish farmed from wild Atlantic salmon, Salmo salar. Ecol Freshwater Fish 13:176-84.

Drivelos SA, Georgiou CA, 2012. Multielement and multi-isotope-ratio analysis to determine the geographical origin of foods in the European Union. TrAC, Trends Anal Chem 40:38-51.

FAO, 2018. Overview of food fraud in the fisheries sector. Fisheries and Aquaculture Circular No. 1165. Rome, Italy.

European Parliament and Council of the European Union, 2013. Regulation of the European Parliament and of the Council of 11 December 2013 on the common organization of the markets in fishery and aquaculture products, 1379/2013/EU. In: Official Journal of the European Union, L354/1-21, 11-122013.

Galindo-Prieto B, Eriksson L, Trygg L, 2014. Variable influence: on projection (VIP) for orthogonal projections to latent structures (OPLS). J Chemom 28:623-32.

Gamboa-Delgado J, Molina-Poveda C, Godínez-Siordia DE, VillarrealCavazos D, Ricque-Marie D, CruzSuárez LE, Gillanders B, 2014. Application of stable isotope analysis to differentiate shrimp extracted by industrial fishing or produced through aquaculture practices. Can J Fish Aquat Sc 71:1520-8

Ghidini S, Ianieri A, Zanardi E, Conter M, Boschetti T, Iacumin P, Bracchi PG, 2006. Stable isotopes determination in food authentication: a review. Ann Fac Medic Vet Parma 2006, 26:193-204.

Giles, MA, Attas EM, 1993. Rare earth elements as internal batch marks for rainbow trout: retention, distribution, and effects on growth of injected dysprosium, europium, and samarium. Trans Am Fish Soc 122:289-97.

Li J, Hong M, Yin X, Liu J, 2010. Effects of the accumulation of the rare earth elements on soil macrofauna community. J Rare Earths 28:957-64.

Li L., Han C, Dong S, Boyd CE, 2018. Use of elemental profiling and isotopic signatures to differentiate Pacific white shrimp (Litopenaeus vannamei) from freshwater and seawater culture areas. Food Control 95:249-56.

Michibata H, 1981. Labeling Fish with an Activable Elemen Through Their Diet. Can J Fish Aquat Sc 38:1281-2.

Mittermüller M, Saatz J, Daus B, 2016. A sequential extraction procedure to evaluate the mobilization behavior of rare earth elements in soils and tailings materials. Chemosphere 147:155-62.

Moreno Rojas JM, Serra F, Giani I, Moretti VM, Raniero F, Guillou C, 2007. The use of stable isotope ratio analyses to discriminate wild and farmed gilthead sea bream (Spaurus aurata). Rapid Commun Mass Spectrom 21:207-11.

Morrison DJ, Preston T, Bron JE, Hemderson RJ, Cooper K, Strachan F, Bell JG, 2007. Authenticating production origin of gilthead sea bream (Sparus aurata) by chemical and isotopic fingerprinting. Lipids 42:537-45.

Noack CW, Dzombak DA, Karamalidis AK, 2014. Rare earth element distributions and trends in natural waters with a focus on groundwater. Environ Sci Technol 48:4317-26.

Ortea I, Gallardo JM, 2015. Investigation of production method, geographical origin and species authentication in commercially relevant shrimps using stable isotope ratio and/or multi-element analyses combined with chemometrics: An exploratory analysis. Food Chem 170:145-53.

Pérez de Nanclares M, Dessen JE, Rørvik KA, Thomassen Y, Thomassen MS, 2016. Feasibility of using rare earth elements (REEs) to mark and identify escaped farmed Atlantic salmon Salmo salar L. Aquacult Res 47:1885-98.

Rim KT, 2016. Effects of rare earth elements on the environment and human health: A literature review. J Toxicol Environ Health Sci 8:189-200.

Serrano R, Blanes MA, Orero L, 2007. Stable isotope determination in wild and farmed gilthead sea bream (Sparus aurata) tissues from the western Mediterranean. Chemosphere 69:107580.

Tanaka H, Ohshimo S, Takagi N, Ichimaru $\mathrm{T}, 2010$. Investigation of the geographical origin and migration of anchovy Engraulis japonicus in Tachibana Bay, Japan: A stable isotope approach. Fish Res 102:217-20. 